\title{
Ilustrações em Livros Infantis: Alguns Apontamentos
} Ilustrations in Children's Books: Some Notes

por Luis Fernando Herbert Massoni

RESUMO

0 estudo engloba literatura infantil e artes visuais, ao abordar a importância das ilustrações presentes em livros infantis e como elas contribuem para a formação de leitores. Possui natureza básica, utiliza fontes bibliográficas e abordagem qualitativa. Abrange considerações sobre as ilustrações e destaca seu papel como parte do discurso gráfico-visual da história. Apresenta as diversas funções desempenhadas pelas ilustrações e os estereótipos representados através de imagens preconceituosas e discriminatórias. Critica a monopolização das ilustrações, pois cria apenas uma imagem feita sobre uma personagem, de forma a limitar a imaginação dos leitores, além da idealização que, às vezes, distorce a ideologia original de algumas histórias. Observa as modificações pelas quais passaram as ilustrações ao aparecerem nos e-books. Mostra características e critérios a serem levados em conta, quando se realiza uma análise de ilustrações.

Palavras-chave ilustrações; livros infantis; discurso gráfico-visual

\section{ABSTRACT}

The study covers childish literature and visual arts, to approach the importance of the illustrations present in children's books and how they contribute to the formation of readers. It has basic nature, use bibliographic sources and qualitative approach. Includes considerations about the illustrations and detaches its role like part of the graphic-visual speech's history. Shows the various functions performed by the illustrations and stereotypes represented through prejudicial and discriminatory images. Criticizes the monopolization of the illustrations, because creates only an image made about a character, such that to limit the imagination of readers, besides the idealization that, sometimes, distorts the original ideology of some stories. Observes the changes in which passed the illustrations when appear in the e-books. Shows the characteristics and criteria to consider when making an illustrations' analysis.

Keywords illustrations; children's books; chart-visual speech 


\section{Introdução}

A infância é uma das fases em que o ser humano mais demonstra curiosidade, vontade de interagir com tudo à sua volta. Nesse período, em especial, o contato com a leitura torna-se importante e proveitoso para desenvolver sua fantasia e criatividade. Segundo Coelho (2000, p. 164), "[...] a literatura infantil ocupa um lugar específico no âmbito do gênero ficção, visto que ela se destina a um leitor especial, a seres em formação, a seres que estão passando pelo processo de aprendizagem inicial da vida [...]".

Ler é uma questão de cidadania, pois um livro aberto é uma janela que mostra uma paisagem da possibilidade de transformação sócio-cultural dos indivíduos que o fazem. Mesmo que seja mediada por um adulto, a leitura é para a criança uma forma de interação com o mundo ao seu redor, descobrindo através das páginas de um livro e/ou e-book novas histórias, cada uma em um contexto, sendo esse realista, ao retratar o meio no qual a criança está inserida, ou fantasioso, levando-a a desenvolver e brincar com sua imaginação.

Magalhães (1987) apresenta a ideia de que o texto só desperta o interesse do leitor infantil quando é adequado para ele. No entanto, para que isso aconteça, são importantes dois aspectos: deve ser propiciada a identificação entre a personagem e a criança, e devem ser preenchidas, por meio da leitura do texto, as lacunas de compreensão do seu próprio pensamento. Bettelheim (1980) afirma que a literatura infantil possibilita às crianças a compreensão do significado de suas próprias vidas, sendo que, segundo o autor, essa é a tarefa mais difícil e também mais importante para os pais. Ele ainda destaca que não há valor na habilidade de ler quando o que se aprendeu a ler não possibilita nenhum acréscimo à vida de quem leu.

É claro que não se pode esquecer do caráter pedagógico dos contos, muito presente nessa literatura, porém deve-se dar ênfase ao seu caráter lúdico, pois, como afirma Coelho, "Aquilo que não divertir, emocionar ou interessar ao pequeno leitor não poderá também transmitir-Ihe nenhuma experiência duradoura ou fecunda." (2000, p. 164). Além disso, o impacto psicológico sobre a criança propiciado pelo conto não é bem sucedido se não cumprir, em primeiro lugar, seu papel enquanto obra de arte (BETTELHEIM, 1980).

0 que se deve pensar, ao ter noção dessas considerações iniciais sobre o livro infantil, é que se esse livro possui uma importância tão grande na vida da criança e seu impacto pode até mesmo modificar a forma como ela vê o mundo, levando-se em conta que possibilita ao leitor "ler-se" nos livros, ou seja, encontrar no livro a compreensão do significado de sua própria vida, é importante que se tenha cuidado ao indicar um livro ou realizar uma contação de histórias, pois há uma grande quantidade de obras no mercado, "[...] algumas muito boas, mas a maioria de qualidade duvidosa [...]", como afirma Jardim (2000, p. 75).

Tendo em vista a importância que possui a leitura na infância, fase na qual os aprendizados conquistados são carregados para o resto da vida, esse artigo se dispõe a refletir sobre as ilustrações presentes em livros infantis, uma vez que 
elas são uma das características que mais elucidam a história e chamam atenção das crianças, sendo, sem dúvida, responsáveis por ampliar o alcance e impacto da leitura e, dessa forma, contribuir para a formação de leitores.

Para tanto, a pesquisa possui natureza básica e utiliza-se de fontes bibliográficas e abordagem qualitativa, se propondo a realizar um levantamento das funções, características e peculiaridades acerca das ilustrações presentes nos livros infantis, levando-se sempre em conta que elas possuem muita influência dentro dessa gama de livros, pois muitas vezes é a ilustração a grande responsável por cativar os leitores e incentivá-los a conhecer a história. Pretende mostrar de que forma elas contribuem para o divertimento, desenvolvimento e compreensão do significado da história e, portanto, da própria vida da criança, sem esquecer que essa característica é importante para o seu desenvolvimento enquanto leitora.

\section{Considerações sobre ilustrações nos livros infantis}

A ilustração é um artifício peculiar utilizado nos livros infantis para chamar atenção das crianças, além de também ser uma imagem que pode substituir um texto, ampliá-lo, adicionar a ele informações, ou também questioná-lo (FREITAS; ZIMMERMANN, 2006-2007), levando-se em consideração que a leitura de imagens antecede à leitura de palavras, e muitas crianças têm contato com as histórias através das imagens. A formação de leitores se fortalece pelo acesso e leitura de diversos tipos de mídias, sejam essas textos ou ilustrações. Conforme Estés (2005), na infância as ilustrações são utilizadas para ancorar a criança na história, prendem o seu interesse até o fim (principalmente no caso de histórias longas). Jardim (2000, p. 76) afirma que quanto menor a idade da criança, "[...] maior deve ser a quantidade e o tamanho das ilustrações. Para leitores em fase de alfabetização, o texto deve ser curto, o vocabulário acessivel e a ilustração, facilitadora da compreensão da história." Cabe ressaltar que, em uma contação de histórias, a ilustração não sobressai às habilidades do contador, pois se este não souber transmitir a história de maneira prazerosa, dificilmente as crianças the prestarão atenção.

Deve-se destacar que as ilustrações nos livros infantis fazem parte do discurso apresentado, levando-se em conta que sua presença é uma característica de tal importância que às vezes a contribuição do ilustrador torna-se tão destacável quanto a do autor do livro. Analisar uma história infantil e desconsiderar as ilustrações nela presentes significa omitir elementos do discurso da história, sendo que as ilustrações assumem o papel de produzir um discurso gráfico-visual (informação verbal)' . A ilustração “[...] estimula o raciocínio e a criatividade do leitor, por

1 Conceito apontado por Paula Mastroberti no III Congresso Internacional de Leitura e Literatura Infantil e Juvenil / II Forum Latino-Americano de Pesquisadores da Leitura, em Porto Alegre, em maio de 2012. 
isso os desenhos devem sugerir mais do que já está expresso no enunciado verbal, evitando a mera descrição gráfica do texto." (JARDIM, 2000, p. 76).

Da mesma forma que o texto do livro infantil deve estabelecer relações com a vida da criança, a ilustração também pode (e deve) desenvolver esse papel, como elemento constituinte do discurso. Percebe-se esse caso, por exemplo, nas ilustrações do livro Gato que pulava em sapato (ALMEIDA, 2002), que se apresentam sob a perspectiva do gato no momento em que mostram, em grande parte da história, apenas as pernas da dona do gato, o que, de certa forma, reflete a própria visão que as crianças têm dos adultos, devido à baixa estatura.

\section{Funções das ilustrações nos livros infantis}

Norteando-se pelo exposto acima, a melhor forma de se iniciar a explanação sobre o impacto das ilustrações no imaginário infantil é justamente apontar as funções que esse discurso desempenha, pois, além de ornar e elucidar o texto, as ilustrações apresentam as seguintes funções²:

a. função representativa: imita a aparência da personagem a qual se refere;

b. função descritiva: trata-se do detalhamento da aparência da personagem;

c. função narrativa: ocorre quando a ilustração situa a personagem representada através de transformação (no estado do ser representado) ou ações (por ele realizadas);

d. função simbólica: quando sugere significado sobrepostos ao seu referente, mesmo que arbitrariamente, como por exemplo as bandeiras nacionais;

e. função expressiva: quando há a revelação de sentimentos e valores do produtor da imagem ou quando ressalta as emoções e sentimentos da personagem representada;

f. função estética: enfatiza a forma da mensagem visual, ou seja, sua beleza;

g. função lúdica: orienta para o jogo, incluindo-se o humor como modalidade de jogo;

h. função conativa: quando orientada para o destinatário, com o objetivo de influenciar seu comportamento, através de procedimentos persuasivos ou normativos;

i. função metalingüistica: o referente da imagem é a linguagem visual ou a ela diretamente relacionado, como citações de imagem, etc.;

j. função fática: a imagem enfatiza o papel de seu próprio suporte;

k. função de pontuação: orientada para o texto junto ao qual se insere, sinali-

2 Informação fornecida por Luís Carmargo em palestra apresentada na Universidade de Karlstad, na Suécia, em outubro de 1999. 
zando seu início, seu fim ou suas partes, nele criando pausas ou destacando alguns de seus elementos.

Camargo (1999) ainda afirma que:

Muito mais do que apenas ornar ou elucidar o texto, a ilustração pode, assim, representar, descrever, narrar, simbolizar, expressar, brincar, persuadir, normatizar, pontuar, além de enfatizar sua própria configuração, chamar atenção para o seu suporte ou para a linguagem visual. É importante ressaltar que raramente a imagem desempenha uma única função, mas, da mesma forma como ocorre com a linguagem verbal, as funções organizam-se hierarquicamente em relação a uma função dominante.

Portanto, ao escolher uma história para contar a uma criança, é válido que se avalie qual a função que o discurso gráfico-visual apresenta, pois a contribuição da ilustração para a história e o impacto que ela terá sobre a criança dependem da função que ela se dispõe a exercer.

\section{Estereótipo, discriminação e preconceito} nas ilustrações dos livros infantis

Abramovich (2004) defende que ao analisar uma ilustração de histórias infantis, não se deve levar tanto em conta a sua qualidade ou se possui uma aparência fantasiosa ou realista, mas que se avalie a presença de estereótipos naquela figura, ou seja, o quanto ela abre espaço para generalizações e preconceitos. Jardim afirma que:

[...] as ilustrações têm servido de veículo para o reforço de estereótipos e preconceitos. Personagens más são invariavelmente feias, enquanto fadas, príncipes, princesas e herois apresentam sempre um ótimo aspecto. A avó é geralmente representada por uma velhinha de cabelos brancos e coque, tricotando em uma cadeira de balanço, e o avô, por um velho gordo, de óculos na ponta do nariz, chinelos e com uma aparência bonachona. Mesmo em livros que contam histórias atuais, a mãe aparece de avental e espanador na mão; o pai, segurando uma pasta ou um jornal. A empregada, o marginal e o operário são quase sempre negros. (2000, p. 76).

Como exemplo de estereótipo presente em ilustrações de livros infantis, pode-se apontar as ilustrações do livro Quem roubou o bisão? (MARANHÃo, 1986), que representam a avó como uma senhora aparentemente muito velha, de óculos, corcunda, calçando chinelos, usando um coque na cabeça e tricotando. É claro que há avós assim, porém a crítica que se faz a esse tipo de representação das avós deve-se a sua generalização, pois nem todas as avós possuem essas características. Hoje em dia, principalmente, as avós têm cada vez menos semelhanças com a avó representada nas ilustrações do livro. 


\section{Monopolização e idealização das ilustrações nos livros infantis}

deve-se tomar cuidado para não escolher uma ilustração que monopolize a figura das personagens, ou seja, é importante que não se apresente apenas uma mesma representação estética de cada personagem para a criança, bem como ela também não deve ser extremamente idealizada a ponto de quebrar a própria ideologia presente nas histórias. Esse argumento se fortalece com a afirmação de Estés (2005), ao alegar que as imagens das personagens criadas pelos artistas muitas vezes se tornam as únicas imagens na mente das crianças - e também na dos adultos.

Deste modo, a criança toma para si aquela representação da personagem como sendo a mais fidedigna, e isso implica na perda de uma ótima oportunidade de exercitar sua criatividade, imaginando qual é a aparência da personagem. É interessante o contato com diversas edições das histórias, de forma que cada uma apresente as ilustrações representando as personagens de maneiras diferentes, para evitar a construção de apenas uma imagem pronta e monopolizada das personagens.

A idealização é outra questão que deve ser avaliada nas ilustrações. Pode-se citar como exemplo o Corcunda, que representa a ideologia de que não se deve julgar alguém pela sua aparência, sendo que há pessoas bonitas que são más e pessoas feias que são boas. Em outras palavras, apresenta a ideia de que pode haver um conteúdo belo dentro de uma embalagem feia ou grotesca. 0 discurso presente em 0 corcunda de Notre-Dame (HUGO, 1831) é, de certa forma, quebrado quando há uma idealização do Corcunda, que em algumas versões da história é belo, quando deveria ser feio.

Estés (2005, p. 28) defende que "Lixiviar as imagens inatas e sempre mutantes da imaginação deteriora a capacidade criativa da pessoa e faz com que ela passe a se abastecer apenas de "imagens feitas'." Portanto, é necessário tomar cuidado ao lidar com livros com ilustrações que apresentem imagens prontas, amáveis e encantadoras, quando na verdade deveriam ser feias e grotescas. A criança tem que saber (e isso não irá traumatizá-la) que ninguém é esteticamente perfeito.

Quando as imagens são amesquinhadas, em versões "bonitinhas", o impacto surpreendente de encontrar beleza e transformação naquilo que se acha mais grotesco, feio, estragado, se perde; o conceito de redenção para todos desaparece. A imaginação é maior do que qualquer material recontado jamais poderá ser. (ESTÉS, 2005, p. 28).

\section{As ilustrações em e-books}

0 advento do e-book serve para desmistificar a ideia de que a tecnologia (através da internet, principalmente) acabará com o hábito da leitura, pois soube congregar as duas coisas, mostrando que até pode ser possível que os livros de papel tradicionais tenham uma queda no uso (ou mesmo deixem de existir com o tempo), mas a leitura não desaparecerá por causa da tecnologia. Mas não será essa questão tratada aqui no que tange aos e-books, e sim a transformação pela qual passaram as ilustrações ao aparecerem neles, pois assim como no livro em papel, no $e$-book as ilustrações continuam presentes. 
A grande novidade (embora já existisse também no livro convencional, devido aos livros pop-up) nas ilustrações presentes nos e-books se dá pelo fato de que há movimentação das imagens, que muitas vezes é possível através do próprio toque na tela, em que se podem mexer os objetos e as personagens de uma lado para outro. Porém, cabe destacar que essa interatividade entre leitor e ilustrações não garante o sucesso da história, pois a ilustração pode até chamar atenção da criança no início, mas a narrativa sim é que tem o poder de garantir o encantamento e, assim, contribuir para a formação do leitor.

\section{Análise de ilustrações em livros infantis}

Ao apreciar as ilustrações presentes em histórias infantis, além de se analisar as características descritas nas seções anteriores, também se deve prestar atenção às seguintes características:

a. Coloração: quando a ilustração é preta e branca, tende a não chamar muita atenção das crianças (principalmente as mais novas), que tendem a preferir ilustrações coloridas, com cores vibrantes;

b. Dimensão: 0 tamanho da ilustração também influi. Um dos motivos é por que, quando a ilustração é muito pequena, fica difícil mostrá-la quando se está contando uma história, principalmente se for contada para muitas crianças. Também é muito utilizada a mescla entre ilustrações e texto, onde o segundo sobrepõe-se ao primeiro;

c. Realismo: deve-se perceber também se a ilustração é realista ou não. Não há um parâmetro que se possa apontar como certo neste quesito, pois há autores que preferem ilustrações realistas e outros que defendem as irrealistas. Estés (2005), por exemplo, afirma que uma boa ilustração deve ser realista, sendo que para desenhá-la, é importante que o ilustrador tenha conhecimentos de anatomia. Para a autora, alguns ilustradores não passam de borradores, sendo que seus desenhos parecem ter sido feitos para ilustrarem revistas açucaradas. Ela afirma que uma boa ilustração deve ser como uma obra de arte, que seja fantasmagóricas, possua sublimidade, denote fome, distorção de escalas, ofensa à perfeição e ilustre anomalias. Por outro lado, Abramovich (2004) alega que não se deve "lutar" por desenhos realistas, que são, segundo a autora, feios e duros;

d. Expressões das personagens: a expressão que cada personagem apresenta é algo que, na maioria das vezes, não é descrito no discurso verbal, sendo possível constatá-la mais facilmente através do discurso gráfico-visual.

e. Contribuição: a ilustração não pode ser apenas uma cópia do que está escrito no texto, ela deve transgredir, mostrar detalhes não relatados no discurso textual, de modo a contribuir com a história e, desse modo, justificar sua existência.

Ao analisar-se uma ilustração infantil, deve-se ter a preocupação de perceber todas 
as características descritas acima, além de reparar no possível fortalecimento de estereótipos e preconceitos. Porém, não apenas esses critérios devem ser levados em consideração, pois a ilustração infantil também deve ser avaliada, bem como 0 livro infantil, pela sua estética e criatividade, pois como já foi citado acima, o livro não atinge impacto psicológico sobre o leitor se não desenvolver, antes disso, seu papel enquanto obra de arte, que propicia prazer e divertimento.

\section{Considerações finais}

A presença das ilustrações é muito importante e deve ser analisada, levando-se em conta a forma como elas desenvolvem as suas diversas funções. Deve-se, ao analisar uma ilustração, perceber se ela abre margem para a intensificação de algum tipo de preconceito, através da disseminação de estereótipos. Não se deve privar ninguém de ter contato com este tipo de ilustração, mas que se apresente e incite a criança a pensar sobre aquela figura, perguntando o que ela acha sobre aquilo e, dessa forma, desenvolver o seu senso crítico, tão importante para o desenvolvimento da cidadania, comentado no início deste artigo.

Cabe salientar que o discurso gráfico-visual, por si só, muitas vezes é o único constituinte de uma história, como é o caso dos livros de imagens. Esse tipo de discurso realiza a ponte leitor-história, no sentido de que torna possivel uma leitura alternativa, que foge da monopolização do padrão de leitura verbal. Por esse motivo, é de crucial importância a ilustração nos livros infantis, pois possibilita às crianças o início à vida como leitoras. 


\section{Referências}

> ABRAMOVICH, Fanny. Como os livros infantis desenham nossas personagens. In: Literatura Infantil: gostosuras e bobices. São Paulo: Scipione, 2004. p. 36-41.

> ALMEIDA, Fernanda Lopes. Gato que pulava em sapato. São Paulo: Ática, 2002.

> BETTELHEIM, Bruno. A psicanálise dos contos de fadas. 10 ed. Rio de Janeiro: Paz e Terra, 1980.

> CAMARGO, Luís. A relação entre imagem e texto na ilustração de poesia infantil. Suécia, 1999. Disponível em: 〈http://www.unicamp.br/iel/memoria/Ensaios/poesiainfantilport.htm>. Acesso em: 21 maio 2012.

$>$ COELHO, Nelly Novaes. A literatura infantil: gênero ou forma? In: Literatura infantil: teoria, análise, didática. São Paulo: Moderna, 2000. p. 163-177. > ESTÉS, Clarissa Pinkola. Contos dos Irmãos Grimm. Ilustrações de Arthur Rackham. Tradução de Lia Wyler. Rio de Janeiro: Rocco, 2005.

> FREITAS, Neli Klix; ZIMMERMANN, Anelise. A ilustração de livros infantis: uma retrospectiva histórica. DAPesquisa, Florianópolis, v. 2, n. 2, ago./2006 - jul./2007. Disponivel em: 〈http://www.ceart.udesc.br/revista_dapesquisa/volume2/numero2 /humanas/Neli\%20-\%20Anelise.pdf〉. Acesso em: 21 maio 2012.

> HUGO, Victor. 0 Corcunda de Notre-Dame. Paris: Scipione, 1831.

$>$ JARDIM, Mara Ferreira. Critérios para análise e seleção de textos de literatura infantil. In: SARAIVA, Juracy Assman (Org.). Literatura e Alfabetização: do plano do choro ao plano da ação. Porto Alegre: ArtMed, 2000. cap. 9.

> MAGALHÃES, Lígia Cademartori. Literatura infantil brasileira em formação. In: ZILBERMAN, Regina; MACALHÃES, Lígia Cademartori (Org.). Literatura Infantil: autoritarismo e emancipação. 3 ed. São Paulo: Ática, 1987. cap. 5.

> MARANHÃO, Haroldo. Quem roubou o bisão? São Paulo: Editorial, 1986.

Luis Fernando Herbert Massoni, estudante do curso de Biblioteconomia, da Universidade Federal do Rio Grande do Sul (UFRCS)

fernandomassoni@hotmail.com 